\title{
UTILIZAÇÃO DE MÉTODOS LÚDICO-EDUCATIVOS NO PROCESSO DE APRENDIZAGEM RELACIONADO À TERAPIA INTRAVENOSA- RELATO DE EXPERIÊNCIA
}

Autores: Nedachi NDL, Serrano CF, Magalhães LS, Grosso R, Almeida S. natasha.lutiis@hc.fm.usp.br Instituto do Câncer do Estado de São Paulo- ICESP

Introdução: O Grupo de Terapia Intravenosa (GTIV) em instituições públicas tem como fundamentação a implantação de boas práticas neste tipo de terapia. Adicionalmente, é necessária a constante busca de estratégias para estimular os profissionais ao maior engajamento destas práticas. Nesse contexto, o GTIV elaborou um evento para melhor compreensão do tema, por meio de processos de aprendizagem lúdico-educativas, favorecendo a autorreflexão dos cuidados prestados pelos profissionais de saúde. Objetivo: Relatar a experiência do GTIV na realização do evento intitulado "TIV WEEK" na obtenção de resultados assistenciais e consolidação do conhecimento da equipe de saúde. Métodos: O evento foi realizado durante cinco dias, utilizando métodos de aprendizagem lúdico-educativos, visando a disseminação de boas práticas em terapia intravenosa. Foram utilizadas as seguintes estratégias: "Rodaa-roda" (roleta graduada com quatro cores, sendo três destas relacionadas a níveis de dificuldade das questões e uma cor relacionada a tarefa "Desafio"), "Painel Coluna Interativa" (fotos de diversos dispositivos intravenosos onde cada um deveria ser relacionado a um tipo de cuidado específico), "Carrinho Itinerante" (com materiais de treinamento, onde o participante joga um dado contendo os dizeres "Verdade ou Desafio? e o participante responderia a uma pergunta ou realizaria uma atividade proposta). Além destas atividades, os participantes foram convidados a assistir um dia de palestras sobre TIV abordando temas como implantação de PICC em serviços públicos, perspectivas futuras para CVC totalmente implantados, entre outros.
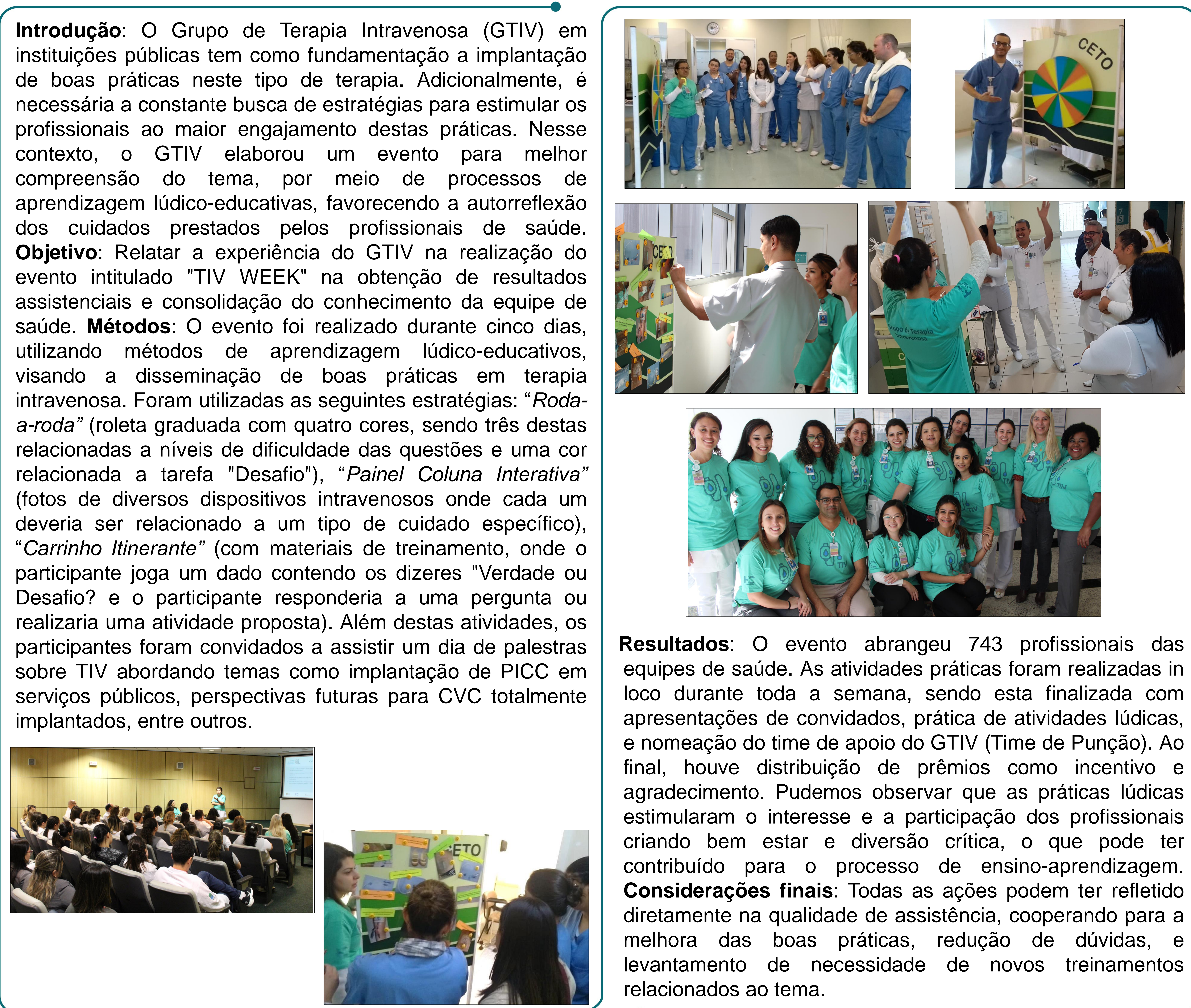

Resultados: $O$ evento abrangeu 743 profissionais das equipes de saúde. As atividades práticas foram realizadas in loco durante toda a semana, sendo esta finalizada com apresentações de convidados, prática de atividades lúdicas, e nomeação do time de apoio do GTIV (Time de Punção). Ao final, houve distribuição de prêmios como incentivo e agradecimento. Pudemos observar que as práticas lúdicas estimularam o interesse e a participação dos profissionais criando bem estar e diversão crítica, o que pode ter contribuído para o processo de ensino-aprendizagem. Considerações finais: Todas as ações podem ter refletido diretamente na qualidade de assistência, cooperando para a melhora das boas práticas, redução de dúvidas, e levantamento de necessidade de novos treinamentos relacionados ao tema.
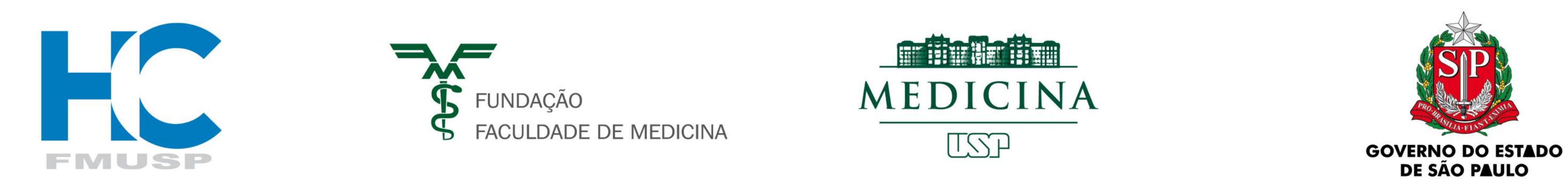